\title{
Darf mir mein Chef Urlaubszeiten vorschreiben?
}

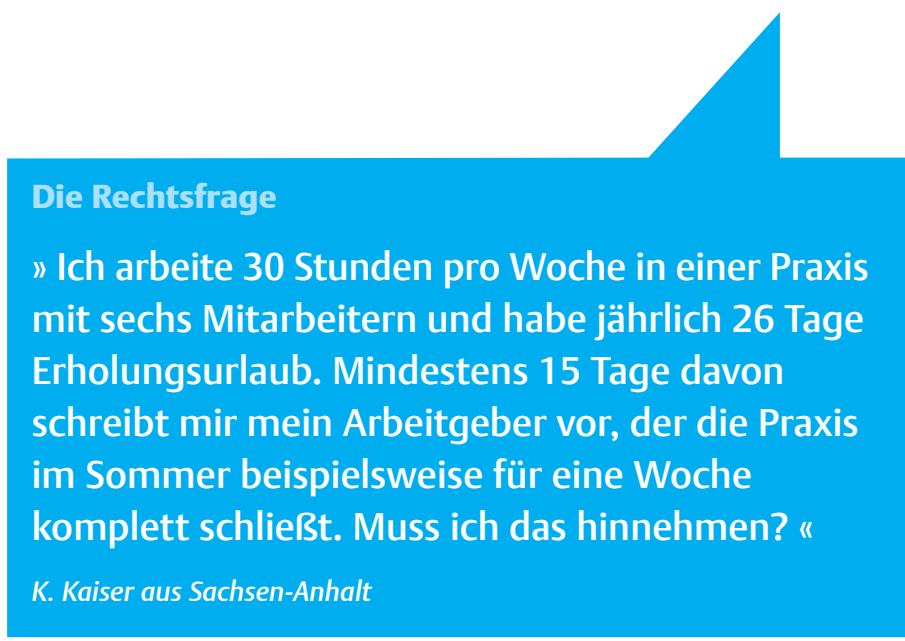

\section{Die Antwort unseres Experten}

Urlaubsanspruch beruht auf dem Arbeitsvertrag. Ein Arbeitgeber muss seinen Mitarbeitern den Urlaub grundsätzlich im jeweiligen Kalenderjahr gewähren und deren Wünsche berücksichtigen. Unter gewissen Voraussetzungen darf er bestimmen, wann seine Mitarbeiter Urlaub nehmen bzw. dass sie ihren beantragten Urlaub nicht nehmen können. Wenn diese keine Wünsche äußern, kann der Chef beispielsweise sowohl die Dauer als auch die Lage des Urlaubs bstimmen. In der Regel erfragt er aber die Wünsche und versucht, ihnen zu entsprechen. Unabhängig davon darf ein Arbeitgeber auch Betriebsferien einführen - wie in Ihrem Fall, wenn die Praxis für eine Woche geschlossen ist. Dann spricht man von Urlaubsgewährung. Sie ist verbindlich und unabhängig von den Wünschen der Mitarbeiter.

Ein Arbeitgeber darf die Urlaubswünsche eines Arbeitnehmers nur dann verweigern, wenn dringende betriebliche Belange oder Urlaubswünsche anderer Mitarbeiter, die unter sozialen Gesichts- punkten den Vorrang verdienen, dagegensprechen. Der Chef kann darauf drängen, dass seine Mitarbeiter den Urlaub zusammenhängend nehmen. Nach dem Bundesurlaubsgesetz darf er den Urlaub sogar nur dann in Teilen gewähren, wenn dringende betriebliche oder persönliche Gründe des Arbeitnehmers dies erforderlich machen. Mindestens ein Urlaubsteil muss zwölf Werktage umfassen. Werktage sind dabei alle Tage mit Ausnahme von Sonntagen und gesetzlichen Feiertagen. In Ihrem Fall heißt das: Ihr Chef kann verlangen, dass Sie mindestens 15 Urlaubstage zusammenhängend nehmen. Sie könnten dem nur mit persönlichen Gründen widersprechen, zum Beispiel, wenn Sie bestimmte Urlaubsteile für eine Fortbildung benötigen. Nicht widersprechen können Sie der Urlaubsgewährung in den Betriebsferien. Sollte Ihr Chef auch die Lage der 15 zusammenhängenden Tage von sich aus bestimmen, können Sie dem - mit Ausnahme der Betriebsferien - widersprechen und auf Ihren Urlaubsantrag verweisen. Diesem muss der Arbeitgeber grundsätzlich folgen oder Ihnen die entgegenstehenden Gründe nennen. Dann können Sie entscheiden, ob Sie diese Gründe akzeptieren, oder versuchen, gerichtlich durchsetzen, dass der Urlaub nach Ihren Wünschen zu gewähren ist.

Karsten Bossow

\section{$\Rightarrow$ Wirft auch Ihr Berufsalltag rechtliche Fragen auf? Dann schreiben Sie an Simone.Gritsch@thieme.de.}

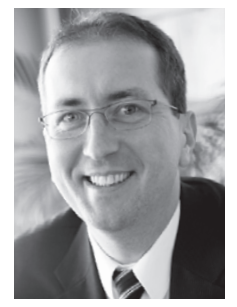

Karsten Bossow ist seit 1999 Rechtsanwalt mit den Tätigkeitsschwerpunkten Arbeits-, Medizin- und Sozialrecht. Seit 2003 ist er Fachanwalt für Arbeitsrecht und seit 2010 Fachanwalt für Medizinrecht. 